Utah State University

DigitalCommons@USU

\title{
Gender Difference in Longitudinal Social and Personal Factors Related to Frequency of Alcohol Consumption of South Korean Adults: A Fixed-Effects Model
}

Baksun Sung

Utah State University

Follow this and additional works at: https://digitalcommons.usu.edu/soc_stures

Part of the Anthropology Commons, Social Work Commons, and the Sociology Commons

\section{Recommended Citation}

Sung, Baksun. "Gender Difference in Longitudinal Social and Personal Factors Related to Frequency of Alcohol Consumption of South Korean Adults: A Fixed-Effects Model." Asia Pacific Journal of Public Health, May 2020, doi:10.1177/1010539520925718.

This Article is brought to you for free and open access by the Sociology, Social Work and Anthropology Student Works at DigitalCommons@USU. It has been accepted for inclusion in Sociology, Social Work and Anthropology Student Research by an authorized administrator of DigitalCommons@USU. For more information, please contact digitalcommons@usu.edu.

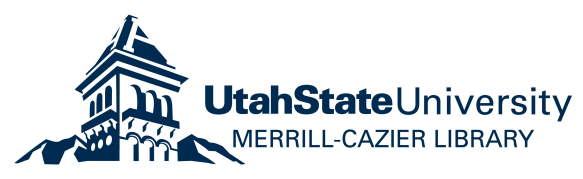


Gender Difference in Longitudinal Social and Personal Factors Related to Frequency of Alcohol Consumption of the South Korean Adults: A Fixed Effects Model

$$
\text { Baksun Sung }{ }^{1}
$$

1. Department of Sociology, Social Work, and Anthropology, Utah State University

* Corresponding author information

Name: Baksun Sung

Phone: 714-900-0117 Fax: 435-797-1240

Institution: Utah State University Department of Sociology, Social Work, and Anthropology

Address: 0730 Old Main Hill Logan, UT 84322-0730

E-mail: baksun777@gmail.com 


\begin{abstract}
The purpose of this study was to examine the longitudinal social and personal factors related to frequency of alcohol consumption by South Korean adults focused on comparisons between the men and women. Data came from the 2005-2016 Korea Welfare Panel Study (KoWePS). A fixed effects model was used to examine the longitudinal correlations between dependent and independent variables. According to the present results, firstly, life satisfaction except for health satisfaction and marital status were not associated with alcohol consumption patterns by men. On the other hand, higher frequency of alcohol consumption by women is negatively associated with various life satisfaction variables and being married. Secondly, income levels were positively associated with higher frequency of alcohol consumption by men, whereas income levels were not associated with alcohol consumption by women. Finally, being employed was positively associated with higher frequency of alcohol consumption by both men and women. In conclusion, there are gender differences in how alcohol consumption is influenced by various socio-cultural and life satisfaction factors in South Korea.
\end{abstract}

Keywords: Alcohol consumption; Gender; A Fixed effects model; Psychosocial; Drinking culture; South Korea 


\section{What We Already Know}

The prevalence of drinking in South Korea is still high. According to Euromonitor's sample, South Korea has the highest strong alcoholic drink consumption in the world. South Korean society is known as the society where drinking is encouraged. In other words, South Korean adults' social life revolves around alcohol. Some studies have reported that there is gender difference in the frequency of alcohol consumption. Social factors including marital status and employment status lead to gender difference in the frequency of alcohol consumption in South Korea.

\section{What This Article Adds}

This study additionally examined gender differences in the association between life satisfaction variables and frequency of alcohol consumption using longitudinal data.

\section{Introduction}

Heavy consumption of alcohol is associated with various disease: such as irregular heartbeat, liver cirrhosis, cancer, and fetal alcohol spectrum disorder. ${ }^{1,2}$ According to WHO Global status report on alcohol and health 2018, approximately 283 million people aged 15 years and over (accounting for 5.1\% of adults worldwide) suffered from an alcohol use disorder (AUD) in 2016 worldwide. Binge drinking resulted in about 3 million deaths (accounting for 5.3\% of all deaths worldwide) per year in 2016 (WHO, 2019). South Korea's alcohol consumption was estimated at 10.2 L/year of pure alcohol compared with 7.3 L/year for the Western Pacific Region and 6.4 L/year for the world average among persons aged 15 years and over in $2016{ }^{3}$ In this regard, South Korea was ranked fifth highest among the Western Pacific countries. ${ }^{3}$ However, there was 
a disparity between the amount of alcohol consumed and the amount of hard alcohol consumed. According to Ferdman \& King (2014), South Koreans drink 13.7 shots of liquor/week on average, which is the most in the world according to results analyzing Euromonitor's sample. ${ }^{4}$ In general, South Korean adults find it difficult to avoid drinking in their social life. ${ }^{5}$ Thus, a lot of drinking occurs after work in South Korea. Company-wide drinking is commonplace in South Korea, referred to as hoesik, which means eating and drinking parties including numerous rounds at multiple venues for organizational socialization. ${ }^{6,7}$ Besides hoesik, many South Korean people drink to improve relations with business partners and friends. ${ }^{8}$ South Koreans consider alcohol as a "social lubricant," as something that helps break the ice among people. ${ }^{9,10}$ According to Korea Health Statistics 2019, the percentage of high frequency of alcohol consumption was $20.6 \%$ for adult males and $6.3 \%$ for adult females in $2017 .{ }^{11}$ (Figure 1 ). This suggests there are gender differences in the frequency of alcohol consumption among South Korean adults. Social learning theory, introduced by psychologist Albert Bandura (1977) suggests that gender roles are acquired through the observation of same-sex models, direct tuition, and modeling behavior. Specifically, modeling of a gender role occurs with same-sex models: the child observes how others behave and then emulates (models) that behavior. Direct tuition refers to socially accepted gender behavior (social approval) is rewarded by parents and peers. At the same time, gender inappropriate behavior is discouraged (social disapproval). ${ }^{12}$ Through social learning theory, it can be assumed that encouraging acceptable gender behaviors caused by various social influences could lead to gender differences in health behaviors and drinking behaviors. According to previous studies about gender differences in the frequency of alcohol consumption among South Koreans, firstly, men are more likely to participate in drinking than women. ${ }^{13}$ Secondly, young women are more likely to drink than older women. ${ }^{14}$ Thirdly, in 
terms of marital status, single women are more likely to engage in binge drinking than married women. In contrast, marital status does not significantly affect drinking status for men. ${ }^{14,15}$ Fourthly, in terms of employment status, employed men tend to engage in binge drinking, whereas employment was not associated with binge drinking for women. ${ }^{15}$ Previous studies have also reported that life satisfaction is negatively associated with higher frequency of alcohol consumption. ${ }^{16,17}$ However, little is known about the influence of life satisfaction on frequency of alcohol consumption among South Korean adults. In addition, most previous studies about alcohol consumption of South Korean adults used cross-sectional data that cannot be used to examine behavior over a period to time. These studies do not ensure representative of population. Therefore, the objective of this study was to identify gender differences in association between the frequency of alcohol consumption and various longitudinal social and personal factors.

\section{Methods}

Data and sample

This study used data from the 2005-2016 Korea Welfare Panel Study (KoWePS). The Korea Welfare Panel (KoWePS) is designed to offer information which helps researchers to analyze dynamic aspects of social factors in response to various needs of people over the cycle of their life for the purpose of improving flexibility and reactivity in policy. In addition, the subjects of the present study were selected to enable comparison between low-income and middle-class families, with the questionnaires focused on various areas relating to social welfare availability. ${ }^{18}$ The target population of KoWePS was all households living in South Korea in 2011. The KoWePS-led survey represented $90 \%$ of the census conducted in 2005 (Island and special 
facilities are excluded). The sampling frame of the KoWePS included 230,000 enumeration districts (EDs). KoWePS selected 517 of these EDs (24,711 households) from the primary survey to identify family income before extracting 446 EDs as the final sample. ${ }^{19}$ The target population was South Korean adults (20-70 years), because this study aims to examine longitudinal social and personal factors related to adulthood alcohol consumption. The final sample included a total of 70,583 person-year observations $(38,571$ person-year observations for men and 32,012 person-year observations for women) after removing missing cases. This study did not require approval from the institutional review board because the KoWePS data is secondary data that does not include personal information.

\section{Measures}

Dependent variable.

The frequency of alcohol consumption. The frequency of alcohol consumption was based on a question about the respondent's average drinking quantity for one year, i.e., "How often do you drink alcohol?" Response options include four point scale with "non-drinker" (0), "1 time per month or less" (1), “2-4 times per month” (2), “2-3 times per week” (3), and “4 times per week or more" (4).

Independent variables

Life satisfaction variables. All seven variables, such as social relations satisfaction, family relations satisfaction, residential environment satisfaction, income satisfaction, job satisfaction, health satisfaction, and leisure satisfaction were categorized into three levels (non-satisfaction; normal; satisfaction). 
Others. Marital status variable was converted to a binary index variable (single; married). Annual income was categorized into three levels (0-29 million South Korean Won; 30 million South Korean Won-49 million South Korean Won; 50 million South Korean Won and more). Employment status was categorized into four levels (employed; self-employed; housewives; unemployed).

\section{Covariates}

Age was a continuous variable. The education level was categorized into four levels (high school diploma or less; some college, no degree; bachelor's degree; postgraduate). Region was categorized into five groups (Seoul; metro cities; cities; county; urban \& rural complex). Religion variable was converted into a binary index variable (yes; no). Current smoking status variable was converted into a binary index variable (smoker; nonsmoker) based on responses to the following item: Do you smoke now?

Statistical Analysis

Descriptive statistics. Descriptive statistics (Table 1) is presented to summarize the demographics and population characteristics.

Fixed effects model. Fixed effects model was used to examine longitudinal social and personal factors associated with frequency of alcohol consumption among South Korean Adults (Table 2). It can be summarized as follow: 


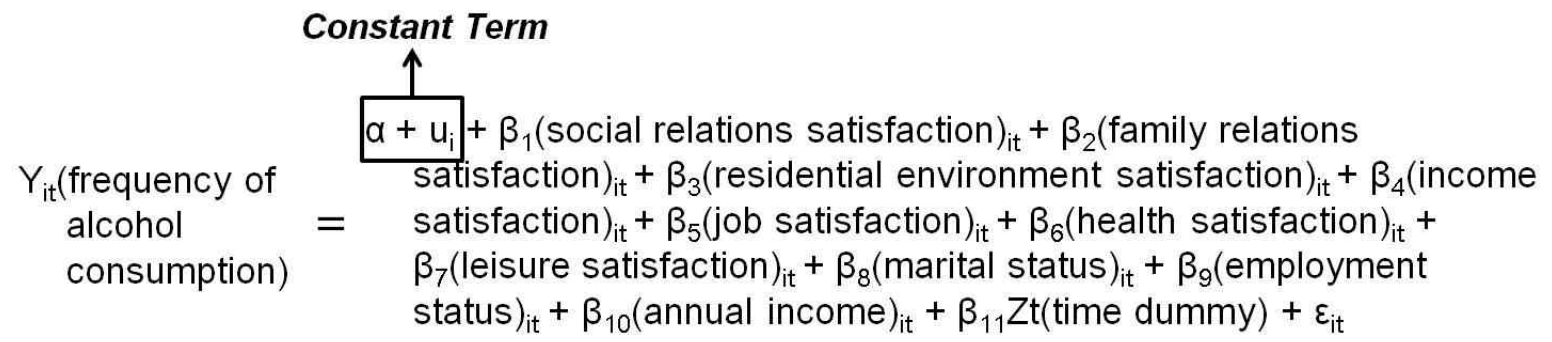

i: Individual

t: Time

$\beta$ : Slope

a: Intercept

$u_{i}$ : Error term from stable characteristics that do not change

over time.

$\varepsilon_{\text {it }}$ : Error term which randomly change over time (white noise).

(This error term is separate from explanatory variables.)

The fixed effects model is a statistical model in which the levels of explanatory variables (model parameters with unobserved differences $\left.\left(\mathrm{u}_{\mathrm{i}}\right)\right)$ are assumed to be fixed and only the dependent variable changes in accordance with the levels of explanatory variables. ${ }^{20,24}$ Also, in fixed effects model, constant term is assumed to be fixed and to vary by time series objects, but slope $\left(\beta_{\mathrm{n}}\right)$ is assumed to be the same by time series objects. ${ }^{21}$ This is in contrast to a random effects model in which some model parameters such as unobserved differences $\left(u_{i}\right)$ are considered random variable. ${ }^{24}$ It means that $u_{i}$ which includes errors from stable personality characteristics is considered parameters in a fixed effects model whereas a random effects model does not include $\mathrm{u}_{\mathrm{i}}$ assuming that covariance between $\mathrm{u}_{\mathrm{i}}$ and explanatory variables is equal to 0 . In addition, a fixed effects model does not include explanatory variables that generally do not change over time. ${ }^{22}$ This is in contrast to random effects models which include explanatory variables that generally do not change over time. ${ }^{22}$ The Hausman \& Taylor test is often used to discriminate between fixed and random effects models. ${ }^{23}$ The null hypothesis is that covariance between $\mathrm{u}_{\mathrm{i}}$ and independent variables was equal to 0 . If the null hypothesis is untrue $(\mathrm{p}<0.05)$, a fixed 
effects (FE) is preferred. On the other hand, if the null hypothesis is true $(\mathrm{p}>0.05)$, a random effects (RE) is preferred. ${ }^{23}$ According to the results of the Hausman \& Taylor test, the null hypothesis is untrue $(\mathrm{p}<0.001)$ (Table 2$)$. Hence, a fixed effects model is more appropriate for this study. Normally, a fixed effects model produces more accurate results than general regression models because fixed effects model can effectively control stable personality characteristics, both measured and unmeasured, that do not change over time such as gender, race, ethnicity, and place of birth. ${ }^{24}$ All statistical analyses were conducted using STATA (version 15.0, StataCorp LLC., College Station, TX).

\section{Results}

Table 1 shows the demographics and population characteristics. The average age of participants was $47.05(\mathrm{SD}= \pm 13.88)$. Age range was between 20 years and 70 years. Men had a higher frequency of alcohol consumption than women (1.970 versus 0.748$)$. People with the highest income levels had a higher frequency of alcohol consumption than people with the lowest income levels (1.532 versus 1.203). Married people had a higher frequency of alcohol consumption than single people (1.435 versus 1.374). Employed people had a higher frequency of alcohol consumption than unemployed people (1.319 versus 1.253$)$.

Table 2 shows the results of multivariate fixed effects regression model of independent variables and the frequency of alcohol consumption among South Korean adult (20-70 years). Unstandardized coefficient from the first fixed effects model (men) indicated that firstly, men with an annual income of 50 million Korean won or more had higher frequency of alcohol consumption than men with an annual income of $0-29$ million Korean won $(\mathrm{B}=0.111, \mathrm{p}<$ 
0.001). Secondly, men who were satisfied with their health status had higher frequency of alcohol consumption than men who were not satisfied with their health status $(B=0.072, p<$ 0.001). Thirdly, self-employed men had higher frequency of alcohol consumption than employed men $(B=0.085, p<0.01)$. On the other hand, unemployed men had lower frequency of alcohol consumption than employed men $(B=-0.176, p<0.01)$.

Unstandardized coefficients from the second fixed effects model (women) for indicated that, firstly, women who were satisfied with social relations had lower frequency of alcohol consumption than women who were not satisfied with social relations $(B=-0.076, p<0.01)$. Secondly, women who were satisfied with residential environment had lower frequency of alcohol consumption than women who were not satisfied with residential environment $(B=-$ 0.056, $\mathrm{p}<0.01)$. Thirdly, women who were satisfied with their income had lower frequency of alcohol consumption than women who were not satisfied with their income $(B=-0.038, p<$ 0.05). Fourthly, married women had lower frequency of alcohol consumption than single women $(B=-0.141, p<0.001)$. Fifthly, unemployed women had lower frequency of alcohol consumption than employed women $(B=-0.103, p<0.001)$.

\section{Discussion}

Life Satisfaction. Life satisfaction variables except for health satisfaction did not affect frequency of alcohol consumption among men. Health satisfaction had a positive effect on higher frequency of alcohol consumption among men. This finding was inconsistent with previous studies indicating that life satisfaction was negatively associated with higher frequency of alcohol consumption. ${ }^{16,17}$ Among women, on the other hand, there were significant associations between frequency of alcohol consumption and the following three life satisfaction variables: 
social relations satisfaction, residential environment satisfaction, and income satisfaction. These three life satisfaction variables had a negative effect on higher frequency of alcohol consumption among women. This finding was consistent with previous studies indicating that life satisfaction was negatively associated with higher frequency of alcohol consumption. ${ }^{16,17}$ As mentioned earlier, South Korean society has been known as a society where drinking is encouraged. In other words, South Korean adults find it difficult to avoid drinking in their social life. ${ }^{5}$ Hence, it can be assumed that South Korean men tend to keep drinking alcohol as long as their health permits regardless of life satisfaction due to drinking culture and social life. In contrast, South Korean women seemed to be less vulnerable to this drinking culture than South Korean men. Rather, life satisfaction seemed to be a more influential factor on alcohol consumption than drinking culture, among South Korean women. Therefore, improving life satisfaction would be a good way to reduce the frequency of alcohol consumption among South Korean women. Marital Status and Income Levels. Firstly, marital status did not affect frequency of alcohol consumption among men. In contrast, being married had a negative effect on higher frequency of alcohol consumption among women. The findings are similar to those reported in previous studies. ${ }^{14,15}$

Secondly, compared to the lowest income group, the higher income groups had a positive effect on higher frequency of alcohol consumption among men. This finding was consistent with research indicating that any alcohol use was more prevalent among individuals with higher income levels. ${ }^{25}$ Among women, however, income level did not affect frequency of alcohol consumption. In South Korea, alcohol use is widely regarded as an important part of social relationships: (1) it is accepted, or even encouraged, to drink during social interactions, accompanied by a meal, (2) in order to improve relations with business partners and friends, and 
(3) to create a congenial mood for adults, especially men. ${ }^{8}$ Hence, it can be assumed that South Korean men with higher income levels were at an increased risk of higher frequency of alcohol consumption. This is because, in South Korea, men with higher income levels were more likely to become involved in social relationships, which could increase the chance for higher frequency of alcohol consumption.

Wilsnack et al $(2000)^{26}$ emphasized that cultural and social structural perspectives can explain gender differences in the frequency of alcohol consumption. Specifically, gender imbalance in social roles leads to gender differences in drinking behavior. This difference is predominantly in regions where gender inequality is a major cultural factor. This is because people in these regions think that women's alcohol consumption has a negative effect on women's social behaviors and responsibilities such as housework and the rearing of children. Hence, gender difference in the frequency of alcohol consumption by marital status can be associated with typical gender role and gender stereotypes in South Korea. The Korean ethnic group was influenced by Confucian culture for a long time. Traditionally, Korean men were more likely to participate in external functions such as village meetings and drinking sessions associated with allocation of resources and production. On the other hand, Korean women were more likely to be involved in house works. ${ }^{27}$ This result can be understood by social learning theory, which claims that encouraging socially acceptable gender behavior based on gender stereotypes should lead to gender differences in social behavior. ${ }^{12}$

Employment Status. Being employed had a positive effect on the frequency of alcohol consumption by both men and women. This may be caused by a company-drinking culture. A lot of drinking occurs during after work hours in South Korea. Company-wide drinking is 
commonplace in South Korea and this is referred to as hoesik, which means eating and drinking parties including numerous rounds at multiple venues for organizational socialization. ${ }^{6,7}$ rho value provides the proportion of the variation in the explanatory variable that can be explained by differences between $\mathrm{u} \_\mathrm{i}$ (stable personality characteristic) in fixed effects model. ${ }^{29}$ Both men (0.593) and women (0.565) have rho value greater than $0.5(50 \%)$ assuming that gender characteristics have a great influence on the association between explanatory variables and frequency of alcohol consumption in South Korea (Table 2). In terms of personality traits associated with higher frequency of alcohol consumption, potential risk factors such as drinking culture can cause endophenotype of binge drinking. ${ }^{30}$ Therefore, it is necessary to take promoting emotional self-control skills, social skills, and decision making into account when conducting alcohol prevention programs to minimize the potential risk factors associated with endophenotype of binge drinking. ${ }^{31}$

The present study's results should be considered in light of several limitations. Firstly, KoWePS measured frequency of alcohol consumption based on a self-report questionnaire. This could result in underestimation of actual frequency of alcohol consumption by recall bias. Secondly, this study was analyzed using a relatively small sample size, because KoWePS is secondary data which may include a lot of missing values. Finally, it was impossible to examine novel cause of gender difference in the frequency of alcohol consumption because all the data gathered are epidemiological and not easy to revise.

\section{Conclusion}

Despite the above limitations, this study provides information from a longitudinal analysis of alcohol use and possible triggers by gender in South Korea. In this sense, the present study 
provides meaningful findings that may facilitate the development of tailored alcohol intervention programs in consideration of gender characteristics. In conclusion, there exist gender differences in frequency of alcohol consumption, which are influenced by various socio-cultural and life satisfaction factors in South Korea. Firstly, life satisfaction except for health satisfaction and marital status did not affect men's frequency of alcohol consumption. On the other hand, various life satisfaction variables and marital status had a negative effect on higher frequency of alcohol consumption among women. Secondly, income levels were positively associated with men's higher frequency of alcohol consumption whereas income levels did not affect women's frequency of alcohol consumption. To sum up, men's higher frequency of alcohol consumption seems to be positively associated with drinking culture and social life, but women's higher frequency of alcohol consumption seems to be negatively associated with life satisfaction and traditional gender role in South Korea. Finally, being employed has a positive relationship with higher frequency of alcohol consumption among both men and women, especially it is influenced by the company drinking culture. In South Korea, the total economic burden of alcohol-related damage is approximately $\$ 28.6$ billion (32.2 trillion Korean won) each year. ${ }^{28}$ Moreover, alcohol-related accidents and diseases have a negative effect on families and the whole society. In consideration of social and health implications of alcohol consumption, gender tailored alcohol intervention programs are needed to reduce alcohol consumption in South Korea. Also, it is necessary to take various socio-cultural and life satisfaction indicators, and their associated gender differences in the frequency of alcohol consumption, into account when preventing excessive alcohol consumption among South Korean adult.

\section{Declaration of Conflicting Interests}


The author(s) declared no potential conflicts of interest with respect to the research, authorship, and/or publication of this article.

\section{Funding}

The author(s) received no financial support for the research, authorship, and/or publication of this article. 


\section{References}

1. National Institutes of Health (NIH). Fetal Alcohol Exposure.

https://www.niaaa.nih.gov/alcohol-health/fetal-alcohol-exposure. Accessed December 16, 2019a.

2. National Institutes of Health (NIH). Alcohol's Effects on the Body. https://www.niaaa.nih.gov/alcohol-health/alcohols-effects-body. Accessed December 16, $2019 b$

3. World Health Organization (WHO). World Health Statistics data visualizations dashboard 2016. http://apps.who.int/gho/data/node.sdg.3-5-viz?lang=en Accessed December 16, $2019 \mathrm{~b}$.

4. Ferdman RA, King R. (2014, February 02). South Koreans drink twice as much liquor as Russians and more than four times as much as Americans. QUARTZ. https://qz.com/171191/south-koreans-drink-twice-as-much-liquor-as-russians-and-more-thanfour-times-as-much-as-americans/

5. Çakar U, Kim, HE. Korea's drinking culture: When an organizational socialization tool threatens workplace well-being. Turkish Journal of Business Ethics. 2015;8(2):289-309. doi:10.12711/tjbe.2015.8.0005

6. Cha C. (2012, May 25). Business traveler's guide to surviving a Korean drinking session. CNN. http://travel.cnn.com/seoul/drink/business-travelers-guide-drinking-korea-213012

7. Cha F. (2014, August 30). 10 things South Korea does better than anywhere else. CNN. http:/edition.cnn.com/2013/11/27/travel/10-things-south-korea-does-best/

8. Ryu SY, Crespi CM, Maxwell AE. Drinking patterns among Korean adults: results of the 2009 Korean community health survey. Preventive Medicine Public Health. 2013;46:183-191. 
http://dx.doi.org/10.3961/jpmph.2013.46.4.183

9. Kim W. Drinking culture of elderly Korean immigrants in Canada: A focus group study. Journal of Cross-Cultural Gerontology. 2009;24(4):339-353. doi: 10.1007/s10823-0099104-Z

10. Yang SH, Kim JH. Drinking habits of employees in farming and fishing communities. Journal of Digital Convergence. 2012;10(10):363-372.

11. Ministry of Health and Welfare (South Korea) (MOHW). Health and welfare statistical year book 2019, Ministry of Health and Welfare; Sejong, Korea. 2019.

12. Bandura A. Social learning theory. Englewood Cliffs, NJ: Prentice Hall., 1977.

13. Jun J, Park H, Sohn S. Trajectories of Korean adults' depressive symptoms and its associations with smoking and drinking: Using Latent Class Growth Modeling. Mental Health and Social Work. 2012;40(3):65-88.

14. Park HY, Jeon J, Son SJ. Gender disparities in typologies of alcohol use and levels of depressive symptoms in Korean adults. Korea Academy of Mental Health Social Work. 2014;5:395-414.

15. Chung S. Examining women's drinking behavior from a gender perspective: Influence of marital status, childcare, employment and sex role attitude. Journal of Critical Social Welfare. 2015;47:158-195.

16. Loivumaa-Honkanen H, Kaprio J, Korhonen T, Honkanen RJ, Heikkilä K, Koskenvuo M. Self-reported life satisfaction and alcohol use: A 15-year follow-up of healthy adult twins. Alcohol and Alcoholism. 2012;47(2):160-168. doi: 10.1093/alcalc/agr151 
17. Tartaglia S, Gattino S, Fedi A. Life satisfaction and alcohol consumption among young adults at social gatherings. Journal of Happiness Studies. 2018;19(7):2023-2034. doi: 10.1007/s10902-017-9907-5

18. Korea Welfare Panel Study (KoWePS). About Koweps. https://www.koweps.re.kr:442/eng/about/purpose.do Accessed December 07, 2019a.

19. Korea Welfare Panel Study (KoWePS). About Koweps. https://www.koweps.re.kr:442/eng/sample/design.do Accessed December 07, 2019b.

20. Salkind NJ. Fixed-effects models. SAGE Research Methods. 2010. https://dx.doi.org/10.4135/9781412961288.n155 Accessed December 16, 2019.

21. Wooldridge JM. Introductory econometrics: a modern approach, Fifth Edition. Cengage Learning. 2015.

22. McCulloch CE, Searle SR, Neuhaus JM. Generalized, linear, and mixed models. New Jersey: Wiley. 2008.

23. Hausman JA, Taylor WE. Panel data and unobservable individual effects. Econometrica. 1981;49(6):1377-1398. doi: 10.2307/1911406

24. Allison PD. Fixed effects regression methods in SAS. Statistics and Data Analysis. SUGI 31. Paper 184-31. 2005.

25. Serdula MK, Brewer RD, Gillespie C, Denny CH, Mokdad A. Trends in alcohol use and binge drinking, 1985-1999: results of a multi-state survey. Am J Prev Med. 2004;26(4): 294298. doi: 10.1016/j.amepre.2003.12.017

26. Wilsnack RW, Vogeltanz ND, Wilsnack SC, Harris R. Gender differences in alcohol consumption and adverse drinking consequences: Cross-cultural patterns. Addiction. 
2000;95(2):251-265. doi: https://doi.org/10.1046/j.1360-0443.2000.95225112.x

27. Midha, A, Kaur S, Niveditha S. Confucianism and changing gender roles.

International Journal of Advance Research, Ideas and Innovations in Technology. 2018;4(1): $347-353$.

28. Lee HK, Lee KS, Kim HS, Jung SK. Measures to facilitate treatment for alcohol harm reduction and prevention. Seoul: Ministry for Health \& Welfare/Catholic University R\&DB foundation. 2012.

29. Bălă RM, Prada EM. (2014). Migration and private consumption in Europe: a panel data analysis. Procedia Economics and Finance. 2014;10:141-149. doi: 10.1016/S2212$5671(14) 00287-1$

30. Oreland L, Lagravineses G, Toffoletto S, Nisson KW, Harro J, Cloninger CR, et al. Personality as an intermediate phenotype for genetic dissection of alcohol use disorder. $J$ Neural Transm. 2018;125(1):107-130 doi:10.1007/s00702-016-1672-9

31. Adan A, Forero DA, Navarro JF. Personality traits related to binge drinking: A systematic review. Front Psychiatry. 2017;28(8):134. doi: 10.3389/fpsyt.2017.00134 
Table 1. Demographics and population characteristics (70,583 person-years), KoWePS, 2005-2016

\begin{tabular}{|c|c|c|c|c|c|c|}
\hline & & $N(\%)$ & $\begin{array}{l}\text { Mean }(y) / \\
\text { Mean Score }\end{array}$ & SD & Min & Max \\
\hline \multicolumn{7}{|c|}{ Control Variables } \\
\hline$\overline{\operatorname{Age}(y)}$ & & $70,583(100.00 \%)$ & 47.050 & \pm 13.876 & 20 & 70 \\
\hline \multirow{2}{*}{ Gender } & Male & $38,571(54.65 \%)$ & 1.970 & \pm 1.349 & & \\
\hline & Female & $32,012(45.35 \%)$ & 0.748 & \pm 1.060 & & \\
\hline \multirow{4}{*}{ Education Level } & Postgraduate & $2,036(2.88 \%)$ & 1.359 & \pm 1.291 & & \\
\hline & Bachelor's degree & $15,437(21.87 \%)$ & 1.494 & \pm 1.240 & & \\
\hline & $\begin{array}{c}\text { Some college, no } \\
\text { degree }\end{array}$ & $8,720(12.35 \%)$ & 1.524 & \pm 1.251 & & \\
\hline & $\leq$ High School & $44,390(62.89 \%)$ & 1.370 & \pm 1.434 & & \\
\hline \multirow{5}{*}{ Region } & Seoul & $11,756(16.66 \%)$ & 1.469 & \pm 1.314 & & \\
\hline & Metro Cities & $20,094(28.47 \%)$ & 1.385 & \pm 1.360 & & \\
\hline & Cities & $26,876(38.08 \%)$ & 1.429 & \pm 1.367 & & \\
\hline & County & $9,814(13.90 \%)$ & 1.361 & \pm 1.447 & & \\
\hline & $\begin{array}{c}\text { Urban \& Rural } \\
\text { Complex }\end{array}$ & $2,043(2.89 \%)$ & 1.512 & \pm 1.405 & & \\
\hline \multirow{2}{*}{ Religion } & Yes & $34,347(48.66 \%)$ & 1.204 & \pm 1.342 & & \\
\hline & No & $36.236(51.34 \%)$ & 1.617 & \pm 1.365 & & \\
\hline \multirow{2}{*}{ Smoking Status } & Smoker & $20,744(29.39 \%)$ & 2.150 & \pm 1.311 & & \\
\hline & Nonsmoker & $49,839(70.61 \%)$ & 1.110 & \pm 1.274 & & \\
\hline \multicolumn{7}{|c|}{ Independent Variables (Life Satisfaction) } \\
\hline \multirow{3}{*}{$\begin{array}{c}\text { Social Relations } \\
\text { Satisfaction }\end{array}$} & Satisfaction & $57,790(81.88 \%)$ & 1.407 & \pm 1.358 & & \\
\hline & Normal & $9,970(14.13 \%)$ & 1.455 & \pm 1.406 & & \\
\hline & Non-satisfaction & $2,823(4.00 \%)$ & 1.456 & \pm 1.470 & & \\
\hline \multirow{3}{*}{$\begin{array}{c}\text { Family Relations } \\
\text { Satisfaction }\end{array}$} & Satisfaction & $53,818(76.25 \%)$ & 1.405 & \pm 1.355 & & \\
\hline & Normal & $12,645(17.92 \%)$ & 1.468 & \pm 1.412 & & \\
\hline & Non-satisfaction & $4,120(5.84 \%)$ & 1.403 & \pm 1.426 & & \\
\hline Residential & Satisfaction & $44,126(62.52 \%)$ & 1.392 & \pm 1.368 & & \\
\hline Environment & Normal & $16,896(23.94 \%)$ & 1.455 & \pm 1.366 & & \\
\hline Satisfaction & Non-satisfaction & $9,561(13.55 \%)$ & 1.457 & \pm 1.380 & & \\
\hline
\end{tabular}




\begin{tabular}{|c|c|c|c|c|}
\hline \multirow{3}{*}{$\begin{array}{c}\text { Income } \\
\text { Satisfaction }\end{array}$} & Satisfaction & $19,346(27.41 \%)$ & 1.415 & \pm 1.338 \\
\hline & Normal & $22,751(32.23 \%)$ & 1.430 & \pm 1.351 \\
\hline & Non-satisfaction & $28,486(40.36 \%)$ & 1.406 & \pm 1.405 \\
\hline \multirow{3}{*}{ Job Satisfaction } & Satisfaction & $36,680(51.97 \%)$ & 1.416 & \pm 1.349 \\
\hline & Normal & $21,664(30.69 \%)$ & 1.373 & \pm 1.372 \\
\hline & Non-satisfaction & $12,239(17.34 \%)$ & 1.493 & \pm 1.422 \\
\hline \multirow{3}{*}{$\begin{array}{c}\text { Health } \\
\text { Satisfaction }\end{array}$} & Satisfaction & $40,570(57.48 \%)$ & 1.536 & \pm 1.334 \\
\hline & Normal & $16,690(23.65 \%)$ & 1.382 & \pm 1.386 \\
\hline & Non-satisfaction & $13,323(18.88 \%)$ & 1.092 & \pm 1.401 \\
\hline \multirow{3}{*}{$\begin{array}{c}\text { Leisure } \\
\text { Satisfaction }\end{array}$} & Satisfaction & $29,513(41.81 \%)$ & 1.425 & \pm 1.348 \\
\hline & Normal & $25,055(35.50 \%)$ & 1.374 & \pm 1.368 \\
\hline & Non-satisfaction & $16,015(22.69 \%)$ & 1.465 & \pm 1.409 \\
\hline \multicolumn{5}{|c|}{ Independent Variables (Others) } \\
\hline \multirow{2}{*}{ Marital Status } & Married & $48,971(69.38 \%)$ & 1.435 & \pm 1.407 \\
\hline & Single & $21,612(30.62 \%)$ & 1.374 & \pm 1.278 \\
\hline \multirow{4}{*}{$\begin{array}{c}\text { Employment } \\
\text { Status }\end{array}$} & Employed & $35,065(49.68 \%)$ & 1.616 & \pm 1.319 \\
\hline & Self-Employed & $11,196(15.86 \%)$ & 1.826 & \pm 1.490 \\
\hline & Housewives & $2,948(4.18 \%)$ & 0.722 & \pm 1.162 \\
\hline & Unemployed & $21,374(30.28 \%)$ & 0.969 & \pm 1.253 \\
\hline \multirow{3}{*}{ Annual Income } & $\geq W 50 \mathrm{M}$ & $28,754(40.74 \%)$ & 1.532 & \pm 1.312 \\
\hline & W30M - W49M & $19,338(27.40 \%)$ & 1.492 & \pm 1.376 \\
\hline & $W 0-W 29 M$ & $22,491(31.86 \%)$ & 1.203 & \pm 1.410 \\
\hline & $\mathrm{SD}=\mathrm{Stanc}$ & viation & & \\
\hline
\end{tabular}


Table 2. Results From Fixed Effects Model, KoWePS, 2005-2016

\begin{tabular}{|c|c|c|c|}
\hline \multirow{2}{*}{ Variables } & \multirow{2}{*}{ Categories } & $\begin{array}{c}\text { Men } \\
(\mathbf{3 8 , 5 7 1} \text { person-years) }\end{array}$ & $\begin{array}{c}\text { Women } \\
(32,012 \text { person-years })\end{array}$ \\
\hline & & $\begin{array}{c}\text { Coef. } \\
\text { [Standard Error] }\end{array}$ & $\begin{array}{c}\text { Coef. } \\
\text { [Standard Error] }\end{array}$ \\
\hline \multicolumn{4}{|c|}{ Control Variables } \\
\hline \multirow{2}{*}{\multicolumn{2}{|c|}{$\operatorname{Age}(y)$}} & $-0.011^{* * *}$ & $-0.021^{* * *}$ \\
\hline & & {$[0.002]$} & {$[0.003]$} \\
\hline \multirow{7}{*}{ Education Level } & $\leq$ High School & Reference & Reference \\
\hline & \multirow{2}{*}{ Postgraduate } & 0.145 & 0.190 \\
\hline & & {$[0.162]$} & {$[0.146]$} \\
\hline & \multirow{2}{*}{ Bachelor's degree } & -0.020 & 0.096 \\
\hline & & {$[0.107]$} & {$[0.103]$} \\
\hline & \multirow{2}{*}{ Some college, no degree } & -0.007 & 0.090 \\
\hline & & {$[0.106]$} & {$[0.098]$} \\
\hline \multirow{9}{*}{ Region } & Seoul & Reference & Reference \\
\hline & \multirow{2}{*}{ Metro Cities } & -0.061 & $-0.177^{* *}$ \\
\hline & & {$[0.069]$} & {$[0.065]$} \\
\hline & \multirow{2}{*}{ Cities } & -0.079 & $-0.126^{*}$ \\
\hline & & {$[0.059]$} & {$[0.055]$} \\
\hline & \multirow{2}{*}{ County } & 0.043 & -0.083 \\
\hline & & {$[0.072]$} & {$[0.069]$} \\
\hline & \multirow{2}{*}{ Urban \& Rural Complex } & -0.052 & -0.174 \\
\hline & & {$[0.121]$} & {$[0.123]$} \\
\hline \multirow{3}{*}{ Religion } & Yes & Reference & Reference \\
\hline & \multirow{2}{*}{ No } & $0.051^{* *}$ & -0.023 \\
\hline & & {$[0.015]$} & {$[0.015]$} \\
\hline \multirow{3}{*}{ Smoking Status } & Nonsmoker & Reference & Reference \\
\hline & \multirow{2}{*}{ Smoker } & $0.253^{* * *}$ & $0.353^{* * 2}$ \\
\hline & & {$[0.021]$} & {$[0.039]$} \\
\hline \multicolumn{4}{|c|}{ Independent Variables (Life Satisfaction) } \\
\hline Social Relations & Non-satisfaction & Reference & Reference \\
\hline Satisfaction & Satisfaction & -0.034 & $-0.076^{* *}$ \\
\hline
\end{tabular}




\begin{tabular}{|c|c|c|c|}
\hline & & {$[0.033]$} & {$[0.029]$} \\
\hline & \multirow{2}{*}{ Normal } & 0.005 & -0.036 \\
\hline & & {$[0.032]$} & {$[0.029]$} \\
\hline \multirow{5}{*}{$\begin{array}{c}\text { Family Relations } \\
\text { Satisfaction }\end{array}$} & Non-satisfaction & Reference & Reference \\
\hline & \multirow{2}{*}{ Satisfaction } & -0.010 & -0.026 \\
\hline & & {$[0.028]$} & {$[0.024]$} \\
\hline & \multirow{2}{*}{ Normal } & 0.013 & -0.001 \\
\hline & & {$[0.028]$} & {$[0.024]$} \\
\hline \multirow{5}{*}{$\begin{array}{c}\text { Residential } \\
\text { Environment } \\
\text { Satisfaction }\end{array}$} & Non-satisfaction & Reference & Reference \\
\hline & \multirow{2}{*}{ Satisfaction } & -0.004 & $-0.056^{* *}$ \\
\hline & & [0.019] & {$[0.017]$} \\
\hline & \multirow{2}{*}{ Normal } & -0.000 & $-0.042^{*}$ \\
\hline & & [0.019] & {$[0.017]$} \\
\hline \multirow{5}{*}{$\begin{array}{c}\text { Income } \\
\text { Satisfaction }\end{array}$} & Non-satisfaction & Reference & Reference \\
\hline & \multirow{2}{*}{ Satisfaction } & -0.020 & $-0.038^{*}$ \\
\hline & & {$[0.017]$} & {$[0.015]$} \\
\hline & \multirow{2}{*}{ Normal } & -0.025 & -0.022 \\
\hline & & {$[0.014]$} & {$[0.012]$} \\
\hline \multirow{5}{*}{ Job Satisfaction } & Non-satisfaction & Reference & Reference \\
\hline & \multirow{2}{*}{ Satisfaction } & -0.019 & -0.019 \\
\hline & & {$[0.018]$} & {$[0.017]$} \\
\hline & \multirow{2}{*}{ Normal } & -0.026 & -0.013 \\
\hline & & {$[0.016]$} & {$[0.016]$} \\
\hline \multirow{5}{*}{$\begin{array}{c}\text { Health } \\
\text { Satisfaction }\end{array}$} & Non-satisfaction & Reference & Reference \\
\hline & \multirow{2}{*}{ Satisfaction } & $0.072^{\text {**** }}$ & -0.031 \\
\hline & & {$[0.019]$} & {$[0.016]$} \\
\hline & \multirow{2}{*}{ Normal } & $0.061^{* *}$ & 0.001 \\
\hline & & [0.019] & {$[0.015]$} \\
\hline \multirow{5}{*}{$\begin{array}{c}\text { Leisure } \\
\text { Satisfaction }\end{array}$} & Non-satisfaction & Reference & Reference \\
\hline & \multirow{2}{*}{ Satisfaction } & -0.016 & 0.015 \\
\hline & & {$[0.016]$} & {$[0.015]$} \\
\hline & \multirow{2}{*}{ Normal } & -0.019 & -0.022 \\
\hline & & {$[0.014]$} & {$[0.014]$} \\
\hline
\end{tabular}




\begin{tabular}{|c|c|c|c|}
\hline \multirow{3}{*}{ Marital Status } & Single & Reference & Reference \\
\hline & \multirow{2}{*}{ Married } & 0.027 & $-0.141^{* * *}$ \\
\hline & & {$[0.037]$} & {$[0.034]$} \\
\hline \multirow{5}{*}{ Annual Income } & $W 0-W 29 M$ & Reference & Reference \\
\hline & \multirow{2}{*}{$\geq W 50 \mathrm{M}$} & $0.111^{* * *}$ & 0.019 \\
\hline & & {$[0.022]$} & {$[0.022]$} \\
\hline & \multirow{2}{*}{ W30M - W49M } & $0.066^{* * *}$ & -0.001 \\
\hline & & {$[0.018]$} & {$[0.018]$} \\
\hline \multirow{7}{*}{$\begin{array}{c}\text { Employment } \\
\text { Status }\end{array}$} & Employed & Reference & Reference \\
\hline & \multirow{2}{*}{ Self-Employed } & $0.085^{* *}$ & 0.017 \\
\hline & & {$[0.025]$} & {$[0.031]$} \\
\hline & \multirow{2}{*}{ Housewives } & -0.023 & -0.061 \\
\hline & & {$[0.071]$} & {$[0.039]$} \\
\hline & \multirow{2}{*}{ Unemployed } & $-0.176^{* * *}$ & $-0.103^{* * *}$ \\
\hline & & {$[0.021]$} & {$[0.016]$} \\
\hline \multicolumn{2}{|l|}{ Constant } & $2.324^{* * *}$ & $2.131^{* * *}$ \\
\hline $\mathbf{u}_{\mathbf{i}}$ & Standard Deviation & 1.093 & 0.822 \\
\hline$\varepsilon_{\text {it }}$ & Standard Deviation & 0.906 & 0.722 \\
\hline rho & Fraction of variance due to $u \_i$ & 0.593 & 0.565 \\
\hline $\begin{array}{c}\text { Hausman \& } \\
\text { Taylor Test }\end{array}$ & Chi-Square & $314.30^{* * *}$ & $355.19^{* * *}$ \\
\hline$* \mathrm{P}<0.05, * * \mathrm{P}<0.01$ & $W=$ South Korean Won & & \\
\hline
\end{tabular}


The percentage of high frequency of alcohol consumption in South Korea (2008-2017)

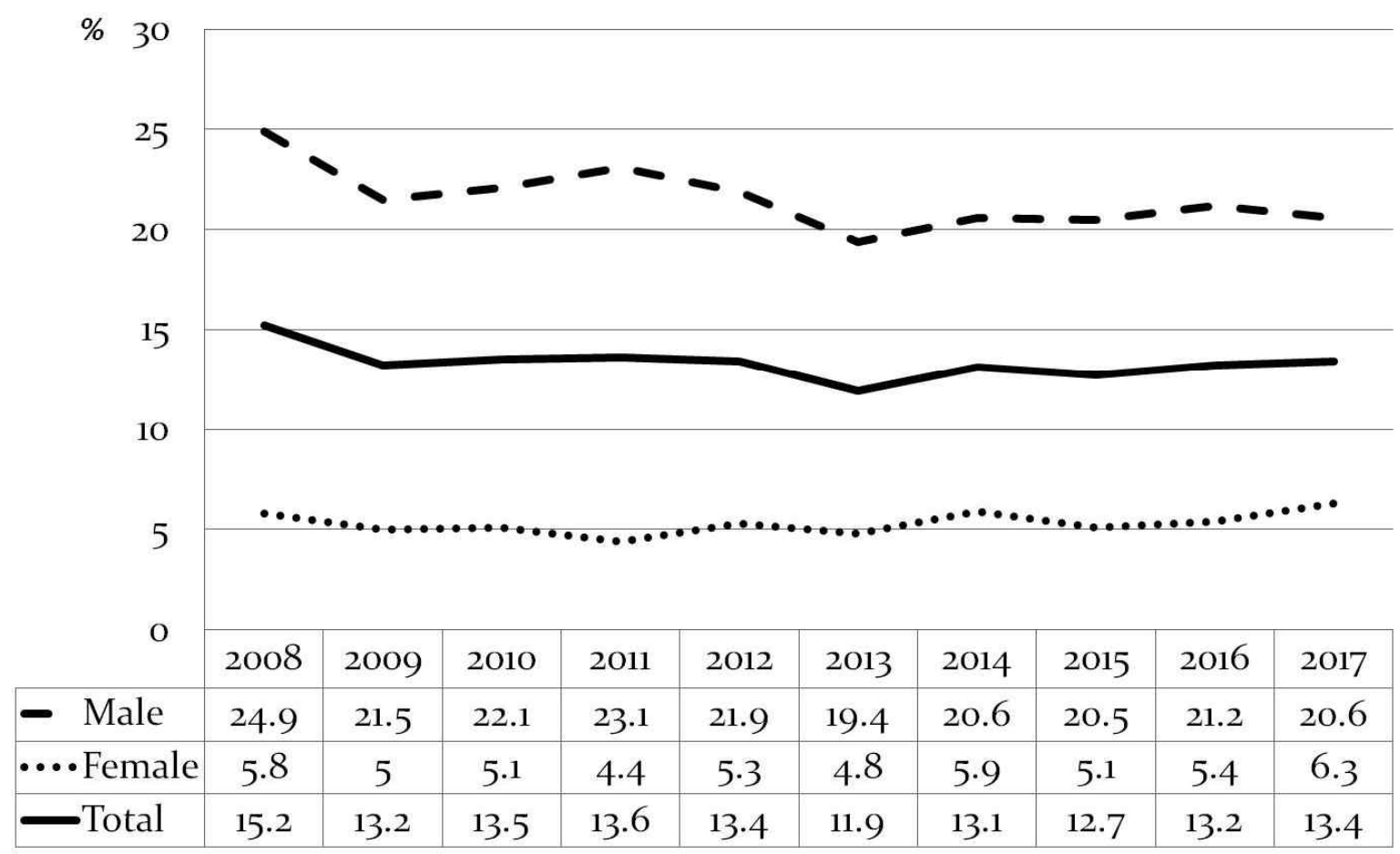

Figure 1. The percentage of high frequency of alcohol consumption in South Korea, 2008-2017.

Source: Ministry of Health and Welfare (South Korea) (MOHW). 2019. 